\title{
Models of Illness and how they help in Holistic Diagnosis for all Doctors -A Brief Review and New Concepts
}

\author{
Durgesh Bailoor* \\ University of Taif, Saudi Arabia
}

Submission: September 06, 2017; Published: December 18, 2017

*Corresponding author: Durgesh Bailoor, Chairman, Integrated Learning Activity ILA Course director health informatics, research methodology, scientific writing, University of Taif, Taif, Kingdom of Saudi Arabia, Email: durgeshbailoor26@gmail.com

Abstract

The area of spirituality and faith in doctors is a highly debated domain. We have two extreme schools one in which doctors believe that all faith is mumbo jumbo and only science can heal. Another school takes a more humane view of patients being a bundle of rationality and beliefs and feel that combination of both spirituality and science can afford a more complete healing. Many of the healers today keep an open mind and take a moderate view of utilizing spirituality in specific perplexing chronic diseases. In this introductory paper a case is made for bio-psychosocio-spiritual model of illness for doctors to weigh and consider.

Keywords: Spirituality and health; Faith in medicine; Model of illness; Bio-psycho-socio-spiritual

\section{Introduction}

In the current era of increasing specialization, where there is a specialist for each finger in the body, all the doctors young and old must take a step back and look into the recent research into the holistic domain of illness in which all the factors; biological, psychological and social determinants of health and disease are considered, in making a diagnosis and recommending a treatment. Another emerging area is the spirituality and faith and how this impacts on the regions of stress control, dealing with cancer and ultimately coping with death in terminal illness. Here the author is proposing an emphasis on a new model of illness which may be termed as the bio-psycho-socio-spiritual model of illness and health behavior. Even though Wang JJ [1] has commented on the gerotranscendence and the peaceful behavior of geriatric patients and the importance of spiritual factors, this author wishes to propose the same theory to encompass the area of chronic pain, depression and even the acceptance of spirituality and spiritual teachers to be in the team of health professionals so that death or terminal illness may be seen not as failure of modern medicine but as in evitable and reasonable transition into death in a patient whose time has come.

\section{BRS- Brief Structured Review}

History of medicine will reveal some very interesting facts on how cave man accepted witch doctor medicine for which there was no scientific basis only faith. Then over centuries we see that physiology and pathology emerging as disciplines and biological factors predominated. Freud S [2] introduced the impact of psychological frustrations and psychiatric etiologies into the domain of physical disease. Ultimately it was George Engel's (1913-1999) biopsychosocial model [3], one of the most important proposition for introducing an holistic and innovative aspect into diagnosis in the last two decades of the 20th century, has emphasized on multi-factorial approach to the etiology of disease calls on doctors to consider patient not as a disease entity but a fully functional social being with a problem (Table 1).

Table 1: A brief explanation of different models and there evolution over a period of time. And how the Bio-psycho-socio-spiritual model appears to be the most comprehensive and humane model to help the doctors in giving a complete care in challenging cases like terminal cancer, atypical pains, depression leading to suicidal actions, unexplained disease syndromes etc.

\begin{tabular}{|c|c|c|c|}
\hline Name of Model & Introduction & Specific References & Summary of the Model \\
\hline Cave man model & Based only on faith and superstitions. & $\begin{array}{c}\text { Rimar Y [4], Kumar } \\
\text { A [5] }\end{array}$ & $\begin{array}{c}\text { These two references emphasize on the } \\
\text { witch craft and on the superstition of } \\
\text { tribals in India which lead to bizarre health } \\
\text { behaviors. }\end{array}$ \\
\hline
\end{tabular}




\begin{tabular}{|c|c|c|c|}
\hline Pre-historical & $\begin{array}{c}\text { Spirits and witch craft was believed to be } \\
\text { responsible for the disease and cures were } \\
\text { often shocking like flogging the patients or } \\
\text { inserting scissors in the skull of the sufferer! }\end{array}$ & Wade DT [6] \\
\hline Bio-medical model & $\begin{array}{c}\text { Failure of bio-medical model was discussed } \\
\text { by Wade et al and they proposed alternative }\end{array}$ & $\begin{array}{c}\text { Only treatment of body as organs and } \\
\text { diseases caused by the physical factors like } \\
\text { infection and blood clots, lack of vitamins } \\
\text { etc. }\end{array}$ \\
\hline $\begin{array}{c}\text { Bio-psycho-social } \\
\text { model }\end{array}$ & $\begin{array}{c}\text { Model based on the results of Engel's studies } \\
\text { in ulcerative colitis, depression and } \\
\text { psychogenic pain, }\end{array}$ & Benning TB [7] & $\begin{array}{c}\text { Biological factors like viruses, psychological } \\
\text { factors like stres and depression and social } \\
\text { factors like loneliness or sexual frustration } \\
\text { as basis for disease. }\end{array}$ \\
\hline $\begin{array}{c}\text { Bio-psycho-socio- } \\
\text { spiritual model }\end{array}$ & $\begin{array}{c}\text { Bailoor as a possible role of spirituality in the } \\
\text { diagnosis and treatment of chronic illnesses, } \\
\text { atypical facial pains and TMjt Myofascial pain } \\
\text { etc [2005] }\end{array}$ & $\begin{array}{c}\text { Katerndahl D [14], } \\
\text { Wang JJ [1] }\end{array}$ & $\begin{array}{c}\text { In this model which is emerging and still } \\
\text { debated by many specialist over the world } \\
\text { proposes that religious faith healers or } \\
\text { preachers may be used in specialized } \\
\text { cases in near death situations, or terminal } \\
\text { cancer cases, chronic pain syndromes, or } \\
\text { severe depression to find alleviation for the } \\
\text { suffering patients. }\end{array}$ \\
\hline
\end{tabular}

The spiritual aspects of health care has roots in ancient Hindu medical philosophy of Ayurveda in which the faith of the person was considered in treatment and prayers and yoga formed an eternal link into the holistic modification of health behaviors for health problems amelioration. In Addition natural herbs and minerals are used treatment of ailments from insomnia to depression and even mundane fever and headaches with practically no side effects [9-11]. MacKinlay EB \& Trevitt C [12] mention that spirituality does not necessarily mean faith in any specific god as per organized religion but a sense of oneness and connectedness of the whole human race and accepting that we have a higher power which may guide us . This author tends to believe very strongly with this concept that belief that the higher power is taking care of us, sort of takes the pressure off the person and lets him relax. This itself may result in reduction of stress and alleviate many of the bodily ailments.

\section{Directions for New Research}

Author sees two primary directions in which the doctors and health care professionals will take:

a) One is that they will integrate the knowledge of various streams of health care like Ayurveda, Yoga and meditation, Homeopathy, Unnani [Persian/Arabic medicine], Herbal medicine and Allopathic medicine [so called modern medicine] and from these options the healer will choose which is appropriate for a particular patient or combination, Instead of sticking to only one of the domains.

b) Second is that matters of spirituality, religion, faith, yoga and meditation will hold increasing emphasis on the history taking, prognosis and holistic management of many chronic diseases. In selected case the preachers of patients faith will be asked to join the team of health care professionals especially so in terminal patients, undiagnosed chronic pain syndromes, chronic depression untreated by medical interventions or undiagnosed fits and seizures which perplex the modern science.

Narayanswamy [13] has focused on a model called ASSET [Actioning Spirituality and Spiritual Care Education and Training] to sensitize the nurses into using spiritual strategies in coping with chronic illnesses. It would be reasonable to assume that even the young physicians and dentists in training would benefit from such emphasis on the spirituality facet in the management of many of the confusing chronic diseases.

\section{Conclusion}

The development of biopsychosociospiritual inventory (BioPSSI) by Katerndahl D \& Oyiriaru D [14]. Was a step in the right direction. This has given future researchers a tool for measurement of the spirituality index in conjunction of biological, psychological and social factors as they impact on the health care. Many of the workers in health care $[15,16]$ have suggested the increasing role of spirituality specially in the field of gerontology and management of elderly and seriously geriatric patients. It is possible that as humans become matured with age, they leans towards the spiritual [17]. A yoga based life style modification has lead to tangible improvement in the cardiovascular risk factors in a specific cohort and emphasized on role of yoga and spiritual counseling in reducing the health risks through preventive strategies [13]. Traditionally the physicians proclaimed that only science and not faith was the cornerstone of healing, but as the new research unravels, they may be enlightened into believing that spirituality, faith and science can all be complementary to each other in a harmonious and complete health care protocol.

\section{References}

1. Wang JJ (2011) A structural model of the bio-psycho-sociospiritual factors influencing the development towards gerotranscendence in a sample of institutionalized elders. J Adv Nurs 67(12): 2628-2636. 
2. Freud S (2012) Critical Introduction to Neuropathology (1885-1887) Sigmund Freud. Published by Katja Guenther, Gerhard Fichtner and Albrecht Hirschmüller. Luzif Amor 25(49): 33-82.

3. Saraga M, Fuks A, Boudreau JD (2014) George Engel's Epistemology of Clinical Practice. Perspect Biol Med 57(4): 482-494.

4. Rimar Y, Rimar D (2003) Witches saints and other diseases. Harefuah 142(5): 383-3866, 396.

5. Kumar A, Pandey R, Singh K, Sharma V (2011) Scissors in brain: an unusual presentation of tribal culture in India. Turk Neurosurg 21(3) 413-417.

6. Wade DT, Halligan PW (2017) The biopsychosocial model of illness: a model whose time has come. Clin Rehabil 31(8): 995-1004

7. Benning TB (2015) Limitations of the biopsychosocial model in psychiatry. Adv Med Educ Pract 6: 347-352.

8. Bailoor DN, Nagesh KS (2005) Fundamentals of Oral Medicine and Radiology. In: Bailoor DN, Nagesh KS (Eds.), Fundamentals of Ora Medicine and Radiology. ( $1^{\text {st }}$ edn), Jaypee Brothers Medical Publishers, India, pp. 1-446.

9. Mason H, Schnackenberg N, Monro R (2017) Yoga and Healthcare in the United Kingdom. Int J Yoga Therap.

10. Kimura K (2017) Yoga Therapy in Japan. Int J Yoga Therap.
11. Butzer B, LoRusso AM, Windsor R, Riley F, Frame K (2017) A Qualitative Examination of Yoga for Middle School Adolescents. Advances in School Mental Health Promotion 10(3): 195-219.

12. MacKinlay EB, Trevitt C (2007) Spiritual care and ageing in a secular society. Med J Aust 186(10 Suppl): S74-76.

13. Narayanasamy A (2006) The impact of empirical studies of spirituality and culture on nurse education. J Clin Nurs 15(7): 840-851.

14. Katerndahl D, Oyiriaru D (2007) Assessing the biopsychosociospiritual model in primary care: development of the biopsychosociospiritual inventory (BioPSSI). Int J Psychiatry Med 37(4): 393-414.

15. Katerndahl DA (2008) Impact of spiritual symptoms and their interactions on health services and life satisfaction. Ann Fam Med 6(5): 412-420.

16. Sulmasy DP (2002) A biopsychosocial-spiritual model for the care of patients at the end of life. Gerontologist 42 Spec No 3: 24-33.

17. Yadav R, Yadav RK, Sarvottam K, Netam R (2017) Framingham Risk Score and Estimated 10-Year Cardiovascular Disease Risk Reduction by a Short-Term Yoga-Based Life-Style Intervention. J Altern Complement Med 23(9): 730-737.

This work is licensed under Creative Commons Attribution 4.0 Licens

DOI: 10.19080/JCMAH.2017.04.555645 